\title{
Interfaces de hipermídia, educação e ferramentas on-line
}

\section{Interface and hypermedias, education and tools on-line}

\begin{abstract}
Resumo: O presente artigo busca levantar aspectos da interface de hipermídia a partir de seu conteúdo, isto é, a partir das mídias que as compõe. Para tanto, procurou-se examinar o estado da arte da convergência dessas mídias para o ambiente digital e a sua utilização como artefato cognitivo buscando avaliar as probabilidades da hipermídia em cumprir o seu potencial didático, utilizando a lógica educativa. Com base numa revisão da literatura, discutem-se estes aspectos e apresentam-se as ferramentas on-line e de autoria disponíveis na web 2.0 organizadas a partir de abordagens cognitivas e potencialidades de aprendizagem desenvolvidas. Constando também de um levantamento sobre novos espaços e ferramentas de comunicação e sua possível apropriação pela Educação.

Palavras-chave: Educação. Comunicação. Hipermídia. Ferramentas On-line. Aprendizagem.
\end{abstract}

Abstract: A present article seek to raise expressions of interface of hypermedia for start of this contents, e.g, for start of medias that compose her a therefore, search itself to examine the condition of art and convergence. From that medias for environment digital and for your utilization since cognitive artifact seeking estimate the likelihood of hypermedia in to carry out your didatics potential, utilizing the logics educative. With basis in a review of literature, discuss itself this expressions and present this tools on-line and of authorship available in web 2.0 organized for start of cognitive to broach and potentiality of understanding developing. Ascertaining also of a raising about new spaces and tools of communication and this possible appropriation by education.

Keywords: Education. Communication. Hypermedia. On-line Tools. Learning.

NEVES, Nasson Paulo Sales. Interfaces de hipermídia, educação e ferramentas on-line. Informática na educação: teoria e prática, Porto Alegre, v. 16, n. 2, p. 169-186, jul./ dez. 2013.

\section{Nasson Paulo Sales Neves \\ Universidade Federal de Alagoas}

\section{Introdução}

0 presente trabalho procura levantar aspectos da comunicação a partir da lógica da Educação, pela necessidade de utilizar estudos interdisciplinares para examinar o uso da interface de hipermídia e as ferramentas on-line entendidas como artefatos cognitivos, buscando avaliar as probabilidades da hipermídia em cumprir o seu potencial didático. Esse viés se torna ainda mais necessário, quando observamos que o desenvolvimento e as mudanças nas comunicações estão impulsionando mudanças culturais ocasionadas pela socialização digital.

Os espaços de comunicação abertos pela conexão mundial de computadores através da internet estão ocasionando mudanças profundas na comunicação e na cultura e, consequentemente, na Educação. Em decorrência das transformações ocasionadas pelas tecnologias da informação e comunicação (TIC) estão se configurando diversas interfaces que passam a ter impacto na educação, mas que ocorrem 
numa velocidade maior do que a capacidade do sistema educacional tem de evoluir e se adaptar a essas mudanças.

A partir da utilização de computadores na comunicação surge a interface digital, um novo meio ambiente em acelerado processo de desenvolvimento. Nesse movimento, muita coisa tem mudado no campo da comunicação e na sociedade. Conforme Coll e Monereo (2010, p. 16):

a internet não é apenas uma ferramenta de comunicação e de busca, processamento e transmissão de informações que oferece alguns serviços extraordinários; ela constitui, além disso, um novo e complexo espaço global para a ação social e, por extensão, para o aprendizado e para a ação educacional.

E como não poderia deixar de ser, a Educação também está se movimentando e tentando se adaptar a essas mudanças. Mas para Coll e Monereo (2010, p. 15) "o impacto da TIC na educação, é, na verdade, um aspecto particular de um fenômeno muito mais amplo, relacionado como o papel dessas tecnologias na sociedade atual". Neste cenário, pesquisadores de diversas áreas buscam entender o impacto das TIC, através de artigos, periódicos, livros e produtos acadêmicos, procurando entender e valorizar esse "novo paradigma tecnológico e cultural no século XXI iniciado com a interface digital e a Internet que em suas diversas formas e manifestações evolutivas" (NEVES, 2006, p. 17), e sua apropriação nos processos educacionais.

Entre as diversas teorias, experiências e projetos postos em prática ou em estudo, podemos vislumbrar algumas mudanças pelo caminho, que o que está em andamento é uma inovação no processo educativo, a partir do conceito de professores e alunos enquanto colaboradores no processo de construção do conhecimento (JONASSEN, 2000); a hipermídia colocaria neste cenário o aluno no lugar de autor, possibilitando que ele construa suas próprias compreensões ao invés de se limitarem a interpretar à compreensão do mundo que lhes é transmitida pelo professor (op. cit.). Mas como colocar em prática esses novos caminhos, essas mudanças, é um desafio a todo processo formativo, seja no modelo formativo presencial, semi-presencial ou a distância.

Um dos problemas de uso das TIC na aprendizagem reside exatamente no não desenvolvimento desses potenciais levantados, e o que podemos perceber, quando da aplicação prática desses modelos, a exemplo do modo presencial, a maioria dos professores ainda não sabem como lidar com as TIC na sala de aula, e quanto a modalidade a distância, os resultados em termos de aprendizagem, pelo menos nas áreas em que o governo federal tem se proposto a investir, tem sido pífios. Podemos confirmar esses dados pelo Censo da Educação Superior do Inep (2009), o qual informa que de 838.125 mil matriculados em cursos de graduação a distância, entre públicos e privados, apenas 132.269 mil se formaram, correspondendo a somente $16 \%$ de concluintes. Isto nos leva a concluir que a modalidade que tem demonstrado melhor integração entre a teoria e a prática, e que melhor tem se adaptado a estas mudanças, no uso de TIC na aprendizagem, é o modelo semi-presencial. É com esta modalidade de ensino que as potencialidades de uso das ferramentas on-line aqui levantadas devem ser encaradas.

Um outro aspecto que podemos observar, segundo Mercado (2009, p.10), é que "o maior problema não é a falta de acesso a informação ou as tecnologias, e sim à pouca capacidade crítica e procedimental para lidar com a varie- 
dade e quantidade de informações e recursos tecnológicos", e a pouca capacidade procedimental na aplicação de TIC na Educação acaba dificultando o desenvolvimento de potenciais de aprendizagem desses artefatos cognitivos e a utilização adequada desses recursos em sala de aula.

Com este estudo esperamos contribuir na discussão de um dos aspectos críticos levantado por Mercado (2009), que é a pouca capacidade procedimental dos professores com relação a uso das TIC. A análise do conteúdo das interfaces de hipermídia, da convergência de mídias e das ferramentas on-line surgidas deste processo, e sua apresentação numa abordagem de aprendizagem, pode servir para auxiliar no desenvolvimento de procedimentos e caminhos para que projetos técnicos pedagógicos incluam o uso de artefatos cognitivos ainda não conhecidos em seus conteúdos e atividades de aprendizagem.

Com base numa revisão de literatura, discutem-se estes aspectos buscando refletir sobre o potencial pedagógico da hipermídia, num cruzamento de áreas da Comunicação, Informação e Educação, procurando mostrar como os reflexos e as mudanças na área da Comunicação e da Cultura alteram a Educação e reforçam a necessidade de apropriação das emergentes ferramentas e recursos surgidas no ambiente da web 2.0. ${ }^{1}$

\section{Hipermídia educativa}

Para refletir sobre o potencial pedagógico da hipermídia educativa, partimos do exame

\footnotetext{
${ }^{1}$ Web 2.0 ou Web Social - evolução ocorrida na internet, com a inclusão de ferramentas on-line de autoria que "permite que as pessoas interajam de forma participativa, dinâmica e horizontal, ampliando as chances de construir coletivamente novos conhecimentos, fruto das intensidades relacionais ocorridas no ciberespaço" (TORRES; AMARAL, 2011).
}

da Comunicação Mediada por Interface. Esse exame se faz necessário, pois a interface de hipermídia é um meio de comunicação em desenvolvimento que vem alterando de maneira profunda a maneira como as pessoas interagem com outras pessoas e com a sociedade, e segundo Coll e Monereo (2010, p. 15): "associado a profundas transformações sociais, econômicas e culturais".

Este aspecto pode ser melhor compreendido quando se analisa o que está acontecendo com a comunicação e a educação após o surgimento da internet, da convergência de mídias e de todo processo de socialização digital. A todo momento surgem novos espaços de comunicação e com eles novas formas de interações sociais, ferramentas on-line, mídias sociais, e com isso mais recursos e potenciais de uso das TIC nos diferentes espaços de aprendizagem, sejam elas presenciais, semi-presenciais ou on-line.

Mas, para entender a velocidade com que surgem novas potencialidades de uso das TIC, é preciso nos aprofundarmos um pouco mais na análise desse "meio de comunicação interativo universal, via computador, da Era da Informação" (CASTELLS, 1999, p. 433), e seu aspecto mais visível, a interface digital.

A compreensão histórica dos processos tecnológicos nos permite afirmar que a partir da utilização de computadores na comunicação, surge a interface digital, um novo meio em acelerado processo de desenvolvimento. Podemos confirmar essa visão em Castells (2001, p. 439), quando observa:

A Internet tem tido um índice de penetração mais veloz do que qualquer outro meio de comunicação na história: nos Estados Unidos, o rádio levou trinta anos para chegar a sessenta milhões de pessoas; a tv alcançou este nível de difusão em 15 anos; a Internet 
o fez em apenas três anos após a criação da teia mundial. O resto do mundo está atrasado em relação à América do Norte e os países desenvolvidos, mas o acesso à Internet e o seu uso os estavam alcançando rapidamente nos principais centros metropolitanos de todos os continentes. Contudo, não deixa de ser importante quem teve acesso primeiro, e a quê, porque, ao contrário da televisão, os consumidores da Internet também são produtores, pois fornecem conteúdo e dão forma à teia. Assim, o momento de chegada tão desigual das sociedades à constelação da Internet terá conseqüências duradouras no futuro padrão da comunicação e da cultura mundiais.

Devido ao fato do usuário desse novo meio de comunicação não ser apenas consumidor, mas também produtor, é que o torna revolucionário, ao colocar o poder da autoria de conteúdo ao usuário, aumentando assim o peso da educação nesse processo, pois é através do viés da educação que será possível dotar as pessoas de capacidade para construírem "simultaneamente as condições materiais para garantir a familiarização de futuros produtores e consumidores do aparato tecnológico, engedrando formas coletivas de beneficiar-se do que a própria tecnologia é capaz de propiciar" (TORRES; AMARAL, 2011, p. 51).

Conforme Santos e Silva (2009, p. 107), tudo muda nesse cenário, ocorrendo "uma mudança da lógica da distribuição (transmissão) para a lógica da comunicação (interação)", possibilitando o entendimento da interface de hipermídia não como um meio de transmissão da informação, como os utilizados na educação à distância via televisão, mas como uma ferramenta cognitiva, reformulando também o centro do processo educativo "de uma preocupação do conhecimento enquanto informação e com o professor enquanto transmissor desse conhecimento (PERKINS, 1986 apud JONASSEN, 2000), para o conceito de professores e alunos enquanto colaboradores no processo de construção do conhecimento (JONASSEN, 2000, p. 233)".

A possibilidade de produzir conteúdo e construir interfaces através de ferramentas on-line trazidas pela web 2.0 nos faz perceber a hipermídia não como fonte de conhecimento a partir do qual se aprende, mas "pensar na hipermídia como uma ferramenta cognitiva com a qual podemos construir e aprender (JONASSEN, 2000, p. 232)", tornando possível assim a viabilização da conexão entre a Educação e a geração atual, conectada ao mundo digital, e configura-se uma espécie de comunicação educativa.

Mas antes de aprofundarmos nas abordagens para se trabalhar a hipermídia na aprendizagem, é preciso examinar mais detalhadamente o aspecto da interface de hipermídia utilizada como meio de comunicação, para podermos entender em qual estágio de desenvolvimento esta interface se encontra para estabelecer parâmetros de sua utilização na mediação pedagógica.

\section{Interfaces, convergência de mí- dia e ferramentas on-line}

No exame do estado atual de nossas interfaces podemos perceber que elas utilizam uma metáfora individual. Embora existam espaços públicos de comunicação, o sistema operacional e as metáforas que dão suportes às nossas interfaces digitais já utilizam metáforas individuais advindas do desktop, com suas pastinhas e lixeiras, que ainda hoje são utilizadas na maioria dos sistemas que operacionalizam os computadores. 
Por ser um meio ambiente ainda em desenvolvimento, a evolução da comunicação por interface se equipara à necessidade do surgimento de novas metáforas coletivas para os ambientes públicos digitais surgidos com a rede mundial de computadores.

Para desenvolver parâmetros/possibilidades para sua transformação em interface coletiva, colaborativa e interativa, este estudo busca cruzar estudos da Comunicação, Informação e Educação, com base na lógica educativa.

Tendo a lógica educativa como parâmetro, procuramos verificar o estado da arte dos conteúdos que formam esta interface, isto é, as mídias (textos, fotos, vídeos, gráficos, animações), e a sua convergência para o ambiente digital, juntamente com um levantamento dos espaços de comunicação surgidos, utilizando para tanto uma organização a partir de abordagens cognitiva para possibilitar o desenvolvimento de procedimentos para projetos pedagógicos.

A necessidade deste estudo deves-se ao fato de que, mesmo com todo o esforço pedagógico em conseguir transformar dados em informação para se chegar ao conhecimento, nem mesmo a fase de busca de dados prescinde de uma problematização sobre como esses dados serão e estão sendo construídos, e o conhecimento dessas potencialidades (MOSTAFA, 2007).

Estudos mais promissores nesse sentido nos apontam para a necessidade de dotar professores da capacidade de conhecer os procedimentos de uso das TIC, desde a busca de dados, até o domínio de ferramentas on-line para editar e produzir conteúdos, e com isso ter elementos para construir interfaces, apresentando essa informação e transformando-a em conhecimento neste processo. Para Jonassen (2000, p. 232), é possível entender a hi- permídia como ferramenta cognitiva, na qual "os alunos aprendem mais através da construção de materiais educativos do que através do seu estudo" Podemos confirmar isso em Cruz (2007, p. 23), quando observa:

se antes de 1995 a produção da EAD era uma tarefa dos profissionais de rádio e TV, com as mídias digitais esse processo também passa pelas mãos de docentes que podem produzir, transmitir e gerenciar cursos e disciplinas na internet, tornando-se autores da produção audiovisual e hipertextual de suas aulas.

Para o professor se tornar autor, isto é, produzir conteúdo para construir interfaces, é preciso dominar alguns procedimentos, que podemos dividir em duas fases: numa primeira fase dominar as ferramentas de autoria de edição e produção de conteúdo, e com esse conteúdo pronto, numa segunda fase, poder construir interfaces. Com relação a esta segunda fase, existem ferramentas on-line na qual o professor só precisaria inserir e formatar o conteúdo por ele produzido ou pelos alunos. Todo o processo de programação para apresentação dos dados seria realizado automaticamente pela ferramenta on-line. Isto já é possível, com os recursos surgidos na web 2.0. Procuramos levantar alguns destes procedimentos, ferramentas e mídias disponíveis de forma on-line, divididas em quatro tipos de abordagens elaboradas por Coll (apud TORRES; AMARAL, 2011), são elas: aprendizagem prática, aprendizagem colaborativa, aprendizagem por referenciação e aprendizagem recíproca.

Um dos objetivos dessa forma de apresentação das ferramentas on-line é realizar um levantamento de novos espaços de comunicação com um olhar na ação educacional. 


\section{Ferramentas on-line na apren- dizagem prática}

$\mathrm{Na}$ aprendizagem prática o aluno aprende fazendo. Neste sentido a ênfase no processo de aprendizagem é a "criação individual e coletiva do conhecimento" (COLL apud TORRES; AMARAL, 2011, p. 63). Essa abordagem de aprendizagem foi uma das beneficiadas pela Web 2.0, ao possibilitar o uso de ferramentas de autoria consideradas essenciais para educação. Conforme Torres e Amaral (2011, p. 51), ao permitir "às pessoas tanto aprender umas com as outras quanto aprender a partir de uma perspectiva na qual elas próprias sejam, simultaneamente, objetos dessa aprendizagem e construtoras do conhecimento".

Dentre as ferramentas on-line dessa abordagem, podemos destacar os wikis, os mapas conceituais, os portais colaborativos e as redes sociais de intercâmbio de conteúdo e participação social. Vamos agora nos aprofundar em alguns dos potenciais desenvolvidos por essas ferramentas na aprendizagem.

Os wikis, as enciclopédias planetárias de conteúdo livres, são ferramentas em que o usuário insere informações que irão formar o conteúdo. Esta ferramenta permite que colaboradores editem artigos e criem outros, sendo, portanto, uma ferramenta que desenvolve potencialidades para a escrita colaborativa.

Já os mapas conceituais, entendidas aqui como "ferramentas gráficas utilizadas para representação de um determinado conhecimento" (OLIVEIRA; SILVA, 2006, p. 83), podem ser utilizados para analisar ou ilustrar a estrutura conceitual de uma fonte de conhecimento. A potencialidade desenvolvida por essa ferramenta permite trabalhar um dos maiores problemas da hipermídia na aprendizagem, que é a integração da informação que o aprendente adquire na hipermídia nas suas próprias estruturas de conhecimento. Esse fato pode ser confirmado em Oliveira e Silva (2006), quando observam que o uso didático dos mapas conceituais permite trabalhar na complexidade do processo de ensino-aprendizagem, exigindo que novos e importantes conhecimentos, relativos aos saberes integradores e pedagógicos sejam acrescidos ao perfil de competências e à atuação docente.

Os mapas conceituais permitem ainda ao professor apresentar conteúdos que já foram apresentados aos alunos de maneira diversificada, criando relações entre conceitos por meios de palavras e imagens. Com isso, segundo Oliveira e Silva (op. cit.), podem representar uma estrutura que vai desde os conceitos mais abrangentes até os menos inclusivos, sendo utilizados, dessa forma, para auxiliar na ordenação e na seqüência hierarquizada dos conteúdos de ensino, de forma a oferecer estímulos adequados ao aluno. No seu uso como ferramenta de ensino, permite ao professor trabalhar a criatividade com os alunos, pois desenvolve a capacidade de organização e a concepção de dados de conhecimento de forma gráfica.

Com relação aos portais colaborativos, são recursos também advindos com o advento da web 2.0, que possibilitam colocar, num mesmo espaço de aprendizagem, diversas ferramentas on-line para edição de conteúdos de diversas mídias. Temos como exemplo de portais colaborativos o creazaeducation.com ${ }^{2}$, um portal no qual é possível encontrar num mesmo espaço, ferramentas para storytelling ${ }^{3}$, ou histórias em quadrinhos on-line para uso didático,

\footnotetext{
${ }^{2}$ Creaza Education - Disponível em: http://www.creazaeducation.com. Acesso em: 13 ago. 2011.

${ }^{3}$ Storytelling - processo na qual se contam estórias de forma on-line, baseado em sistemas de RPG e adaptado para o meio digital.
} 
um editor de vídeos on-line, uma ferramenta on-line de mapa mental e um editor de sons. Os vídeos e áudios editados podem ser utilizados como conteúdo para os mapas mentais e para as histórias em quadrinhos.

Como outro exemplo de portal colaborativo podemos citar os sistemas de publicação de notícias como o Wordpress ${ }^{4}$. Esta ferramenta permite trabalhar com facilidade a inserção de conteúdos de textos, fotos, vídeos, arquivos anexados, players de vídeo, realizar buscas dentro do próprio conteúdo, entre outros recursos. Por trabalhar como um gerenciador de conteúdo, permite publicar e gerenciar vários blogs. O professor pode utilizar esta ferramenta para gerenciar diversas disciplinas que ministra, além de permitir que os alunos criem blogs em espaços destinados a entrega de trabalhos, criando portifólios para cada matéria. Esta ferramenta possui mais estudos na área da Comunicação. Ainda é um recurso a ser apropriado pela Educação.

Com o surgimento de portais colaborativos e com eles os sistemas de gerenciamento de conteúdo (SGC), tornou-se possível o agrupamento de diversas ferramentas on-line de edição de conteúdo de mídias, permitindo ao professor organizar diferentes espaços de aprendizagem e produzir, transmitir e gerenciar conteúdos para cursos e disciplinas pela internet, tornando-se mediador para que os alunos produzam materiais de ensino, desenvolvendo potencialidades para o pensamento complexo, ao dotá-los de capacidade para "decidir como capturar um vídeo, criar imagens e animações e programar estes elementos para inserção na apresentação" (JONASSEN, 2000, p. 248 ).

\footnotetext{
${ }^{4}$ Wordpress - Sistema de publicação de notícias on-line. Disponível em: http://www.wordpress.com. Acesso em: 13 ago. 2011.
}

Quanto as ferramentas de redes sociais de intercâmbio de conteúdos e participação social é interessante destacar seu importante papel sociocultural na sociedade contemporânea, pois permite que as pessoas interajam de forma coletiva e atuem como multiplicadores e organizadores de uma dada comunidade. Segundo Ribas e Zaviani (2008, p. 3), esses "atores específicos compartilham informações, pesquisas, dados relevantes para aquela comunidade. Ou seja, a comunicação se dá de maneira rápida e direcionada para um público específico".

As TIC, ao trazer o redimensionamento do espaço público, possibilita desenvolver interatividade e conexão à nível global, trazendo com isso o uso massificado de ferramentas como Facebook, Orkut, Twitter, YouTube, entre outros. A Educação pode trabalhar as potencialidades desenvolvidas por essas ferramentas objetivando "a investigação e a proposição de soluções sobre temas específicos, o diálogo conceitual interdisciplinar e a metacognição" (COLL apud TORRES; AMARAL, 2011, p. 63) nas atividades de aprendizagem.

\section{Ferramentas on-line na apren- dizagem colaborativa/social}

$\mathrm{Na}$ abordagem da aprendizagem colaborativa/ social, o aluno aprende através da interação com os parceiros, com ênfase no processo de aprendizagem a partir de "processos comunicacionais entre os pares" (COLL apud TORRES; AMARAL, 2011, p. 63).

As potencialidades desenvolvidas pelas ferramentas utilizadas nessa abordagem podem variar conforme a ferramenta, que vai desde auxiliar, explicar, ilustrar, relacionar e contribuir para amplificar ações estabelecidas pelos 
professores, como para mostrar os avanços das tarefas de aprendizagem. Além disso, permitem ainda a gestão de conteúdos, a troca de ideias e amplificação da capacidade de entendimento da realidade.

Dentre as ferramentas on-line encontradas podemos citar: blogs, microblogs, wikis, chats, e-mail, portais colaborativos, sites de criação e armazenamento de vídeos e áudios (entrevistas, debates, conferências, reportagens, apresentações) e também as redes sociais de intercâmbio de conteúdos e participação social. Vamos nos aprofundarmos em duas delas, por possuírem mais literatura e pesquisa na área, são elas os blogs, e os sites de criação de vídeos e áudios.

Os blogs, como ferramentas on-line na educação, permitem ao professor desenvolver potenciais de gestão de conteúdo e a troca de idéias. Conforme Mercado e Sobral (2008, p. 4):

blogs podem ser utilizados como suporte pedagógico em situação de aprendizagem, possibilitar o acesso à informações de diferentes formas por meio de sons, imagens e textos, permitindo ao aluno obter, comparar e analisar informações, interagindo num espaço de escrita eletrônica com ensino contextualizado.

A ferramenta blog permite também aos professores trabalhar a ideia de portifólio, possibilitando que os alunos possam acompanhar o desenvolvimento de sua aprendizagem, "desenvolvendo o hábito de registro, gerenciar informações e transformação da informação em conhecimentos". Ainda conforme Mercado e Sobral (2008, p. 4):

A possibilidade de alteração do próprio ambiente é uma característica que diferencia os blogs de outros ambientes usados para a aprendizagem on-line, abre espaço para a emergência da autoria, que se manifesta quando os alunos produzem textos próprios, mas, também, quando começam a transformar o ambiente, tanto no aspecto estético como no estrutural.

Por ser uma ferramenta on-line de fácil utilização, e ser oferecida de forma gratuita por grandes portais e sites de armazenamento e busca, o blog se difundiu de forma bastante rápida pelo mundo, tornando-se uma fonte de informação e conhecimento popular e sendo cada vez mais utilizado como ferramenta pedagógica.

Já as ferramentas on-line de criação e armazenagem de vídeos e áudios permitem desenvolver, assim como o blog, potencialidades para a gestão de conteúdos, como também para o desenvolvimento do pensamento complexo, como a capacidade para decidir como capturar um vídeo, criar imagens e animações e programar estes elementos para inserção na apresentação (JONASSEN, 2000).

Uma ferramenta interessante que permite capturar e baixar vídeos da internet é o Atube Catcher ${ }^{5}$, que permite baixar vídeos do maior repositório de audiovisual do mundo, o Youtube. Com esta ferramenta, também é possível converter um vídeo em diversos formatos (mp4, wmv, avi, IPAD 1, IPOD 1, DVD, gif, flv) e editar para utilizar em interfaces e projetos educativos.

Como exemplo de ferramenta on-line de edição de vídeo podemos citar o site stroome. $\mathrm{com}^{6}$, que permite a edição on-line de imagens, arquivos de vídeos ou fotos; envio de imagens originadas de mídias móveis; criação de comunidades e conexão com outros usu-

\footnotetext{
5 ATube Catcher - Disponível em: http://atube-catcher.softonic.com.br/. Acesso em: 18 jul 2011.

${ }^{6}$ Stroome - Disponível em: http://www.stroome.com. Acesso em: 18 jul. 2011.
} 
ários através destas comunidades; publicação de conteúdos em mídias sociais como Facebook, orkut, twitter; recursos de edição como remixagem, cortes e transições de forma on-line e colaborativa.

Ferramentas que permitem trabalhar a convergência de mídias só se tornaram possíveis após a evolução da grande rede para a web 2.0 e sua nova forma de utilização da internet, na qual é possível ter acesso a recursos de programas que rodam de forma on-line e gratuita a partir de páginas disponibilizadas por empresas desenvolvedoras, partindo do princípio de uso da internet como um sistema operacional, isto é, uma plataforma gráfica na qual rodam programas com recursos e funções que antes só eram possíveis por softwares instalados em um computador off-line (TORRES; AMARAL 2011, p. 53).

Essa perspectiva surgida com a web 2.0 segue a tendência mundial para a mobilidade e a portabilidade da chamada computação nas nuvens, conceito na qual o computador seria simplesmente uma plataforma de acesso às aplicações que estariam em uma grande nuvem - a Internet, possibilitando a computadores menos potentes se conectar à Web e utilizar todas as ferramentas on-line, seguindo o exemplo que o Google ${ }^{7}$ propõe com o Google Docs, Gmail e tantas outras aplicações.

A disponibilização de recursos de programas de edição e produção de conteúdos de forma coletiva e on-line através da grande rede está transformando a interface de hipermídia num espaço de aprendizagem e o desenvolvimento do potencial para a autoria, a convergência e o compartilhamento de conteúdo de diversas mídias, e com isso facilitando a construção de interfaces de hipermídia como abordagem de

\footnotetext{
7 Google - Disponível em: http://www.google.com. Acesso em: 18 jul. 2011.
}

aprendizagem coletiva, interativa e colaborativa, entendida conforme Torres e Amaral (2011, p. 52), "como o processo de construção do conhecimento decorrente da participação, do envolvimento e da contribuição ativa dos alunos na aprendizagem uns dos outros".

E a participação ativa do usuário, seja aluno ou professor, reveste-se de uma necessidade ainda maior quando observamos que na perspectiva da web 2.0 o "usuário é o elo mais importante, e sua participação ativa na configuração do meio ambiente digital é que dá sentido aos serviços oferecidos" (NAFRÍA, 2007 apud QUADROS et al., 2011, p. 31).

Essa evolução da interface de hipermídia a torna uma poderosa ferramenta de aprendizagem em tempos de socialização digital, ao levarmos em conta o aspecto da hipermídia como ferramenta cognitiva, como conhecimento enquanto construção, e ao mesmo tempo contribuindo para uma melhora real da educação, pois a combinação da criatividade e complexidade exigida para se conceberem produtos multimídia (cultura dos jovens) é motivadora e confirma seu potencial eficaz como ferramenta cognitiva (JONASSEN, 2000).

\section{Ferramentas on-line na apren- dizagem por referenciação}

Na aprendizagem por referenciação o aluno aprende pesquisando, tendo como ênfase no processo de aprendizagem a "identificação e organização das fontes de informação e conhecimentos" (COLL apud TORRES; AMARAL, 2011, p. 63).

Dentre as potencialidades desenvolvidas pelas ferramentas utilizadas nessa abordagem podemos citar o fato de que: 
contribuem para que os alunos identifiquem e organizem conteúdos relevantes de informação e conhecimentos de maneira a obterem um repertório bibliográfico para auxiliá-los na produção individual e/ou coletiva de conhecimentos, e promover aprendizagens recíprocas (op. cit., 2011, p. 63).

Além dessas potencialidades, podemos citar também o fato dos alunos aprenderem a procurar diversas fontes, desenvolverem a capacidade de análise e a interpretação da informação encontrada para identificar e interpretar padrões e assim produzir uma nova informação a partir de um dado pesquisado, transformando informação em conhecimento.

Com relação as ferramentas on-line agrupadas nessa abordagem podemos citar os sites de buscas de conteúdos, as bibliotecas virtuais, os repositórios de base de dados e os sites de e armazenagem de vídeos e áudios (entrevistas, debates, conferências, reportagens, apresentações).

Merecem destaques os sites de busca de conteúdos, as bibliotecas virtuais e os repositórios de base de dados.

As potencialidades desenvolvidas por essas ferramentas representam bem as transformações que as TIC vem possibilitando na forma da pesquisa e da divulgação científica, bem como as mudanças culturais que vem acontecendo no mundo. Podemos confirmar isso em Neves (2006, p. 30), quando observa que:

a busca de mais informação acaba gerando novas formas estéticas e culturais, pois a possibilidade de acessar, enviar, receber e alterar modelos, arquivos e consultar referências permite experimentar novas maneiras de utilizar as informações encontradas, perpetuando aquela máxima que diz que na natureza nada se perde, nada se cria, tudo se transforma. No meio digital haveria um processo parecido, onde uma realização disponibilizada alimenta a necessidade de informação de outro trabalho para um novo significado para esta realização que por sua vez vai servir como fonte de inspiração para outro projeto e alimentará novamente o ciclo criativo.

Outro aspecto que podemos examinar nas ferramentas de busca de conteúdo, é que elas revelam a importância da interface digital nesse cenário, ao tornar visível o mundo digitalizado, permitindo a troca de quantidades ilimitadas de informação, sob as mais diferentes formas através das redes globais e fazendo com que a própria tecnologia e os meios de comunicação avancem a saltos cada vez maiores. Com isso mudou-se a percepção humana de tempo e espaço e a nossa maneira de ver o mundo e lidar com a Educação. Isto é o que se pode observar em Johnson (2001, p. 8):

A tecnologia costumava avançar em estágios mais lentos, mais diferenciados. O livro reinou como meio de comunicação de massa preferido por vários séculos; os jornais tiveram cerca de 200 anos para inovar; até o cinema deu as cartas durante 30 anos antes de ser rapidamente sucedido pelo rádio, depois pela televisão, depois pelo computador pessoal. A cada inovação, o hiato que mantinha o passado a distância ficou menor, mais atenuado. Isso não significou muito nos avanços que foram o livro ou o jornal ao longo dos séculos - para não mencionar a escala milenar do pintor das cavernas -, mas à medida que foram se abreviando, os estágios começaram a interromper os ciclos de vida dos seres humanos individuais. Rousseau viveu a vida inteira sob o feitiço da prensa tipográfica. Freud nasceu nos dias de glória do telégrafo e percorreu todo o caminho até os primeiros balbucios da televisão. Há uma espécie de conhecimento a ser revelado nessas interrupções, nessas descontinuidades, como os cortes transversais dialéticos de Encouraçado Potemkin de Eisenstein, (outro notável 
artista-engenheiro). A explosão de tipos de meios de comunicação no século $X X$ nos permite, pela primeira vez, apreender a relação entre a forma e o conteúdo, entre o meio e a mensagem, entre a engenharia e a arte.

Nesse cenário, torna-se mais urgente que o professor domine e tenha acesso a ferramentas de pesquisa on-line, pois conforme Santos e Machado (2010, p. 1), esses acervos digitais disponíveis on-line constituem as novas bases de investigação, construção e socialização do conhecimento, e ao acelerar mudanças culturais reforçam a necessidade de reformular a Educação e inovar o papel do professor:

Todavia, por não haver a possibilidade de construir conhecimento sem acessar e dominar informação (já que informação é a matéria-prima do conhecimento) não convém deixar de fora nenhum suporte, o que faz da internet uma nova e necessária alternativa para alcançar com precisão este substrato da construção do conhecimento.

Por exemplo, ao utilizar sites de busca de conteúdo, como o Google 8 , se o professor souber como proceder para utilizar a ferramenta de forma correta, pode ensinar aos alunos formas de pesquisa em que só apareçam conceitos, em vez de páginas de empresas ou textos de notícias, diminuindo redundância de informações. São conhecimentos como esses que tornam o ato de pesquisar mais proveitoso, revelando a necessidade do professor adquirir competências procedimentais para enfrentar os desafios implicados na utilização das TIC no ensino.

Outro aspecto que podemos destacar para o uso de ferramentas de bibliotecas virtuais e de repositórios de base de dados é o fato de

\footnotetext{
${ }^{8}$ Google. Disponível em: http://google.com. Acesso em: 18 jun. 2011.
}

que para estudar em base de dados, isto é, onde estão armazenadas as informações que compõem o conteúdo informacional do sistema, é preciso buscar uma aproximação com os conhecimentos da Ciência da informação, pois é necessário estudar além da transformação da informação em conhecimento, aprender a gerenciar, armazenar, produzir e distribuir informações no ambiente digital. A interdisciplinaridade se faz novamente presente.

Autores como Mostafa (2007), procuram fazer essa ponte, ao apresentar a área da $\mathrm{Ci}$ ência da Informação e seus objetos de estudo no mesmo movimento em que esses objetos de estudo são pensados na inter-relação com a Educação. Segundo a autora, para a educação, "o importante sempre foi transformar informação em conhecimento. Autonomia, aprender a aprender, aprendizagem significativa, re-significação, metodologia de projetos são todas expressões que fazem parte do ideário pedagógico do século 21" (MOSTAFA, 2007, p. 9).

Nesse sentido, segundo a autora, a pesquisa em grupo, o estímulo à dúvida são estratégias de ensino muito valorizadas hoje no processo ensino-aprendizagem.

\section{Ferramentas on-line na apren- dizagem recíproca}

$\mathrm{Na}$ abordagem da aprendizagem recíproca, a forma de aprender se dá através do compartilhamento. Essa abordagem tem como ênfase no seu processo de aprendizagem a colaboração e a integração de esforços para formação de redes de aprendizagem. Entre as principais ferramentas podemos citar: os portais colaborativos, os vídeos educativos, os wikis, os blogs, os microblogs, as ferramentas de autoria 
e edição de conteúdo, os mapas conceituais e as redes sociais de intercâmbio de conteúdos e participação social.

Dentre as potencialidades desenvolvidas por essas ferramentas podemos citar o fato de propiciarem, contribuírem, desenvolverem e propulsionarem um diálogo coletivo, colaborativo e interdisciplinar; a troca de ideias; a gestão de conteúdos; a investigação coletiva; a visão integrada dos conteúdos e a metacognição.

Destacamos as ferramentas vídeos educativos e as ferramentas de autoria e edição de conteúdo.

Os vídeos educativos possuem uma relevância muito grande na Educação, pois a geração atual, além de interagir com facilidade no mundo digital, também é uma geração mais visual. O vídeo é uma linguagem que aproxima a Educação dos jovens e crianças. Já existe uma convergência do meio audiovisual bastante avançada, talvez uma das mais estabilizadas no meio digital. Formatos de vídeo em Flash ${ }^{9}$ e sites de armazenamento de vídeos como o Youtube ${ }^{10}$, tornaram a disseminação do formato de vídeo popular na internet, tornando a utilização da linguagem audiovisual fácil e de baixo custo.

O sucesso dessa ferramenta foi tão grande, que o Youtube criou o YoutubeSocial, ferramenta que permite sincronizar vídeos entre vários computadores e o TeacherTube ${ }^{11}$, uma ferramenta on-line que possui recursos para

\footnotetext{
${ }_{9}$ Flash - formato de vídeo e linguagem de programação que transforma imagens gráficas em representações matemáticas, e que são carregadas conforme são exibidas. Após seu surgimento, a linguagem de vídeo e animação tornaram-se mais populares na internet.

10 Youtube - repositório de vídeo popular na internet, um dos responsáveis pela popularização e difusão de vídeo on-line. Disponível em: http://www.youtube.cm. Acesso em: 18 jun 2011.

11 TeacherTube - repositório e ferramenta de exibição de vídeo voltado para a educação. Disponível em: http:// www.teachertube.com. Acesso em: 18 jun 11.
}

professores trabalharem conteúdos audiovisuais de forma on-line, podendo formar comunidades para compartilhar vídeos, documentos, áudio, fotos, criar canais e comunidades de estudo, além de ferramentas para organizar e planejar aulas de forma on-line.

Como destaque podemos citar ainda ferramentas como o Animoto.com ${ }^{12}$, que permitem trabalhar narrativas animadas para a web utilizando fotos, áudio e pequenos vídeos, e páginas que permitem trabalhar com videocast como o JustTV ${ }^{13}$, podendo ser utilizadas em videoconferências. Não existem muitos estudos sobre o uso dessas ferramentas no processo educativo.

Autores como Garcia Garcia, Garcia Fernandes e Souza (2010), Nakashima e Amaral (2006) ao proporem o domínio de elementos da narrativa audiovisual como uma possibilidade teórica para o professor produzir conteúdo audiovisual para aplicar em plataformas digitais, como a lousa digital interativa, também observam que seu uso em sala de aula não garante a aprendizagem, mas para os estudantes é um elemento interessante e ainda atrativo.

Conforme Neves (2006), para que o uso da linguagem audiovisual interativa sob enfoque educacional ocorra é preciso que o som e a imagem sejam tratados da mesma forma com que se trata a palavra; é preciso ensinar às pessoas a ler as imagens e os sons da mesma forma como elas lêem as palavras, o que possibilita construir interfaces utilizando os recursos da hipermídia e da interatividade. E essa competência cognitiva precisa ser trabalhada na formação dos professores, de modo gradual, juntamente com as técnicas e os códigos

\footnotetext{
12 Animoto - site de edição on-line de vídeos e animações. Disponível em: http://www.animoto.com. Acesso em: 18 jun 11. 13 JustTV - ferramenta on-line que permite arquivar e exibir videocast para exibição de vídeos ao vivo através de webcams podendo ser utilizado para videoconferência. Disponível em http:// www.justtv.com.br. Acesso em: 18 jun 11.
} 
da linguagem audiovisual. Podemos perceber a emergência do domínio desse conhecimento pelos professores em Costa (2005 apud BASSO; AMARAL, 2006, p. 59), quando observa:

O aprendizado da linguagem verbal falada ou escrita leva anos e envolve o conhecimento de códigos, assim como uma série de exercícios ortográficos, sintáticos e gráficos para que o aprendiz possa ficar à vontade para expressar seus pensamentos e idéias. Com as linguagens técnicas não é diferente, embora muitas vezes as pessoas pensem que se tratando de uma tecnologia, basta a posse do equipamento e as instruções funcionais a respeito de seu uso. No entanto, o aprendizado de qualquer mídia é igualmente complexo e exige que as pessoas incorporem aos poucos as diferentes etapas de alfabetização.

Com relação as ferramentas de autoria e edição de conteúdo, podemos aí incluir todas as ferramentas que trabalham com a edição on-line de áudio, fotografia e vídeos.

Na edição de conteúdo de áudio, podemos incluir ferramentas que possibilitam a convergência da mídia rádio e seu uso na aprendizagem. Autores como Francisco e Sobral (2010) e Silva Costa (2010), relatam experiências e teorias sobre o uso da mídia rádio como recursos didático nas práticas docentes, e a necessidade de trabalhá-lo como um instrumento no processo de ensino aprendizagem. No entanto, existe pouca literatura que trabalhe na definição de metodologias de uso do rádio na sua versão digital. Em seu formato digital, o rádio pode ser utilizado de duas formas: o áudio divulgado pela internet convergindo do seu formato analógico para formatos digitais como o $\mathrm{mp}^{14}$, e arquivados de forma que possam

\footnotetext{
14 Mp3 - formato de áudio digital comprimido que permite o envio e armazenamento de arquivos pela rede, muito utilizado em mídias móveis e aparelhos de som digitais.
}

ser baixados ou ouvidos através da audiostreaming, ou no formato webrádio, que utiliza a tecnologia de podcast para envio distribuição de conteúdos de rádio totalmente produzidos de forma digital.

No formato webrádio, os arquivos de áudio podem ser enviados para os agregadores de conteúdos ${ }^{15}$, ou ficarem disponíveis em um repositório, para serem acessados pelo usuário. Não existem muitos estudos de uso de agregadores de conteúdo ou conteúdo de podcast na aprendizagem. Essa constitui-se uma ferramenta a ser apropriada na formação de professores e seu posterior uso em sala de aula.

Como destaque de ferramenta on-line de edição de conteúdo de áudio podemos citar a Audioexpert.com ${ }^{16}$, através do qual se edita músicas, converte e permite salvar e exportar os arquivos em diferentes formatos ( $\mathrm{mp} 3$, wav, gp3).

Quanto a edição de conteúdo fotográficos, podemos incluir também os gráficos e a animação neste levantamento de ferramentas. Como ferramenta on-line para edição de conteúdo de fotos, podemos destacar a ferramenta picnik. com $^{17}$, que permite ajustar pequenas falhas, melhorar qualidade, cortar, redimensionar, mudar a cor, além de diversos outros recursos de edição de imagens.

Dentre os autores que estudam a utilização de fotografias na aprendizagem, podemos citar Machado (2009), que apresenta estudo interessante sobre grupos de interesse na web, criados a partir da arte fotográfica, no flickr.

\footnotetext{
${ }^{15}$ Agregadores de conteúdo - ferramenta on-line de divulgação de conteúdo produzido por um site ou blog, informando aos assinantes da página atualizações como arquivos e conteúdos novos disponibilizados.

${ }^{16}$ Audioexpert - ferramenta on-line para edição de áudio. Disponível em: http://www.audioexpert.com. Acessada em: 14 ago. 2011.

17 Picnik - ferramenta de edição on-line de fotos. Disponível em: http://www.picnik.com/. Acessada em: 14 ago. 2011.
} 
$\mathrm{com}^{18}$, propondo uma interface entre antropologia, fotografia e ciberespaço.

Conforme Santos (2009), na comunidade virtual existente no flickr.com, pessoas interessadas na arte da fotografia se encontram para visualizar as produções imagéticas dos participantes e:

comentar cada uma delas por meio de um espaço próprio para o diálogo, como se fosse um tipo de "fórum de discussão" ilustrado. Ali a cada dia os membros postam suas fotos, tecem comentários de suas produções e das alheias e ainda travam conversas informais por meio da postagem dos comentários nas páginas de cada um.

Estudos sobre de utilização de imagens na aprendizagem ainda são escassos. A Educação poderia se apropriar de estudos realizados no campo da Comunicação e da Antropologia para trabalhar metodologias de uso dessa mídia. Como exemplo podemos citar as pesquisas na área da semiótica, que poderiam auxiliar a desenvolver metodologias para examinar a imagem e sua apropriação na aprendizagem.

Com relação à edição de vídeos, Basso e Amaral (2006), nos demonstram que a importância do domínio da linguagem audiovisual advém da necessidade do professor dar conta das novas formas de interface e adaptação à linguagem audiovisual interativa.

Como destaque para ferramentas on-line que permite editar vídeos podemos citar o VideoToolBox.com ${ }^{19}$ - ferramenta para edição de vídeo on-line que permite converter para diversos formatos, cortar cenas, adicionar quadros, sons e legendas para vídeos com muita facilidade.

\footnotetext{
18 Flickr - comunidade de aficcionados por fotografia, que criam perfis e inserem suas produções fotográficas. Disponível em: http://www.flickr.com. Acessado em: 18 jun. 2011.

${ }^{19}$ Videotoolbox - ferramenta de edição on-line de vídeos. Disponível em: http://www.videotoolbox.com. Acessado em: 14 ago. 2011.
}

O conhecimento pelos professores dessas ferramentas converte-se num aspecto interessante para a aprendizagem, pois permite que ele se torne um autor de conteúdos de materiais didáticos, incorporando a capacidade de contar histórias audiovisuais, e com isso encontrar novas formas de descrever assuntos mal compreendidos pelos alunos com outro enfoque, pois alunos que não acompanham uma explanação oral, talvez consigam entender melhor o conteúdo tendo uma fonte de conhecimento a linguagem audiovisual e digital da interface de hipermídia. Precisamos apropriá-las.

\section{Conclusão}

Nos levantamentos de literatura sobre uso e apropriação de ferramentas on-line colaborativas e artefatos cognitivos, podemos perceber lacunas existentes.

A falta de estudos críticos sobre interfaces de hipermídia, seu conteúdo e ferramentas reflete a falta de estabilização do ambiente na qual esses novos espaços de comunicação e aprendizagem ainda vicejam. Tudo converge ou está para convergir. Isso tem gerado um ambiente em que o excesso de informação e a emergência de novos recursos são uma constante, com suas múltiplas linguagens advindas das TIC na qual os meios audiovisuais se firmam como preponderantes. É com esses elementos que a Educação tem que trabalhar, para conseguir se conectar a geração atual de jovens e crianças nascidas nesse tempo acelerado pela luz da interface digital.

Não surpreende, portanto, existirem tantas ferramentas on-line disponíveis com diferentes tipos de abordagens de aprendizagem no universo da web 2.0 que ainda não foram apropriados pela educação. 
Aprender a trabalhar o conteúdo dessas interfaces de hipermídia, suas ferramentas on-line, é o primeiro passo para alcançar e superar a lacuna entre os valores educacionais ainda não totalmente potencializados e reconhecidos nas tecnologias digitais de comunicação e informação.

Os caminhos nos levam a constatar que essas diferentes interfaces colaborativas, coletivas e interativas e suas ferramentas on-line favorecem o processo educativo ao possibilitar avanços na aprendizagem. Isso é possível através do uso das diversas fontes e recursos e ferramentas on-line que permitem lidar com todos os tipos de configurações possíveis, bem como trabalhar comunidades de prática utilizando hipermídia educativa e diversos artefatos digitais em função de uma atividade, levando em conta o contexto e a cultura na qual tem lugar, proporcionando a interação social (JONASSEN, 2000).

Nessa perspectiva, podemos levantar que alguns caminhos de uso de TIC na educação são mais promissores que outros, nos levando a defender os modelos conceituais baseados na reflexão e comunicação de ideias. Nesse sentido, trabalhar modelos de aprendizagem sustentados pela ideia de que o conhecimento é conseqüência de uma construção de significados, resultante da reflexão e integração ativada pelo aprendente aliada a noção de experiência social e o pensar no seu próprio processo cognitivo adquire um valor prepoderante (BIDARRA, 2009), pode facilitar aos professores lidar com esse cenário de excesso de informação. É possível, portanto, pensar na interface da hipermídia não como fonte de conhecimento a partir do qual se aprende, mas numa perspectiva de incorporar competências cognitivas na qual professores e alunos se tornem aptos a aprender através do processo de construção de interfaces e materiais didáticos (JONASSEM, 2000).

Saber quais ferramentas disponíveis, bem como suas potencialidades, torna-se hoje necessidade para os educadores, não só pelo fato de serem capazes de responder às exigências da socialização digital, como também para que esses recursos não sejam subutilizados, como vem ocorrendo hoje em muitas experiências de utilização de TIC nos processos educacionais.

\section{Referências}

BASSO, I.; AMARAL, S. Competências e habilidades no uso da linguagem audiovisual interativa sob enfoque educacional. ETD - Educação Temática Digital, Campinas, v.8, n.1, p.49-71, dez. 2006. Disponível em: http://www.fae.unicamp.br/revista/index.php/etd/article/view/2134. Acesso em: 27 abr. 2011.

BIDARRA, José. Aprendizagem multimedia interativa. In: MIRANDA, Guilhermina L. Ensino on-line e aprendizagem multimedia. Lisboa: Relógio D’Água, 2009, p. 352-84.

CASTELLS, Manuel. A sociedade em rede. São Paulo: Paz e Terra, 1999. 
CASTELLS, Manuel. A galáxia da internet: reflexões sobre a internet, os negócios e a sociedade. Rio de Janeiro, 2003.

COLL, César; MONEREO, Carles e colaboradores. Psicologia da educação virtual: aprender e ensinar com as tecnologias da informação e da comunicação. Porto Alegre: Artmed, 2010, p. 15-6.

CRUZ, Dulce M. A produção audiovisual na virtualização do ensino superior: subsídios para a formação docente. ETD - Educação Temática Digital, v.8, n.2, p. 23-44, jun. 2007. Disponível em: http:// www.fae.unicamp.br/revista/index.php/etd/article/view/1759. Acesso em: 30 abr. 2011.

DOS SANTOS, R.; MACHADO, G. Biblioteca digital e pesquisa: interfaces do acesso à informação digital na formação do professor pesquisador. Educação a Distância e Práticas Educativas Comunicacionais e Interculturais-EDaPECI, n.4, abr. 2010. Disponível em: http://www.edapeci-ufs.net/revista/ ojs-2.2.3/index.php/edapeci/article/view/37. Acesso em: 06 maio 2011.

FRANCISCO, Deise J.; SOBRAL, Soray B. Rádio educação: a trajetória do programa rádio Educ-Se. Educação a Distância e Práticas Educativas Comunicacionais e Interculturais-EDaPECI, n.5, ago 2010. Disponível em: Acesso em: 06 maio 2011.

GARCíA GARCíA, F., GARCIA FERNANDEZ, R., SOUZA, K. Lousa Digital Interativa: avaliação da interação didática e proposta de aplicação de narrativa audiovisual. ETD - Educação Temática Digital, Campinas, v.12, n.esp., p. 92-111, mar. 2011. Disponível em: http://www.fae.unicamp.br/revista/index.php/ etd/article/view/2285. Acesso em: 27 abr. 2011.

JOHNSON, Steven. Cultura da interface: como o computador transforma nossa maneira de criar e comunicar. Rio de Janeiro: Jorge Zahar, 2001.

JONASSEN, David H. Computadores, ferramentas cognitivas: desenvolver o pensamento crítico nas escolas. Lisboa: Porto Editora, 2000, p. 229-54.

MACHADO, Glaucio J. Grupos de interesse, fotografia e acoplamento: o caso flickr.com. E como a educação pode tirar proveito disso. Educação a Distância e Práticas Educativas Comunicacionais e Interculturais-EDaPECI. 3, dez 2009. Disponível em: http://www.edapeci-ufs.net/revista/ojs-2.2.3/ index.php/edapeci/article/viewArticle/27. Acesso em: 23 maio 2011.

MERCADO, Luis P. (Org.) Integração de mídias nos espaços de aprendizagem. Em Aberto. Brasília: Instituto Nacional de Estudos e Pesquisas Educacionais Anísio Teixeira (Inep). v. 22, n. 79. Janeiro, 2009.

MERCADO, Luis P.; Sobral, Maria N. Tic em blog na formação docente superior: narrativa de um formador. Educação a Distância e Práticas Educativas Comunicacionais e Interculturais-EDaPECI. 
5, set. 2010. Disponível em: http://www.edapeci-ufs.net/revista/ojs-2.2.3/index.php/edapeci/article/ view/57. Acesso em: 23 maio 2011.

MOSTAFA, S. Ciência da informação e educação. ETD - Educação Temática Digital. v. 8, n.2, p. 1-11, jun. 2007. Disponível em: http://www.fae.unicamp.br/revista/index.php/etd/article/view/1757. Acesso em: 27 abr. 2011.

NAKASHIMA, R.; AMARAL, S.. A linguagem audiovisual da lousa digital interativa no contexto educacional. ETD - Educação Temática Digital, Campinas, v.8, n.1, p. 33-48, dez. 2006. Disponível em: http://www.fae.unicamp.br/revista/index.php/etd/article/view/2133. Acesso em: 27 abr. 2011.

NEVES, Nasson P. Comunicação Mediada por Interface. Maceió: Edufal, 2006.

OLIVEIRA, E; SILVA, M. Mapas conceituais e aprendizagem no ciberespaço: uma reflexão sobre didática e partituras musicais. ETD - Educação Temática Digital. v. 8, n.1, p.72-89, jun 2006. Disponível em: http://www.fae.unicamp.br/revista/index.php/etd/article/view/2135. Acesso em: 27 abr. 2011.

QUADROS, Cláudia; CAETANO, Kati; LARANJEIRA, Álvaro (Orgs.). Jornalismo e convergência: ensino e práticas profissionais. Covilha: Labcom, 2011.

RAMAL, Andrea C. Educação na cibercultura: hipertextualidade, leitura, escrita e aprendizagem. Porto Alegre: Artmed, 2002.

RIBAS, C.; ZIVIANI, P. Mediação, circulação e uso da informação no contexto das redes sociais. ETD Educação Temática Digital. Campinas, v.9, n.2, p.1-19, jun. 2008. Disponível em: http://www. fae.unicamp.br/revista/index.php/etd/article/view/1587. Acesso em: 27 abr. 2011.

SANTOS, Edméa; SILVA, Marcos. Desenho didático para educação on-line. Em Aberto, Vol.: 22, n. 79. Instituto Nacional de Estudos e Pesquisas Nacionais Anísio Teixeira (Inep). Brasília, Janeiro 2009.

SILVA COSTA, J. O rádio como interface pedagógica na prática docente: a experiência do programa de formação continuada de professores em Mídias na Educação. Educação a Distância e Práticas Educativas Comunicacionais e Interculturais-EDaPECI, n. 4, abr. 2010. Disponível em: http://www. edapeci-ufs.net/revista/ojs-2.2.3/index.php/edapeci/article/view/39. Acesso em: 06 maio 2011.

SILVA, Marco. Sala de aula interativa. 5. ed. São Paulo: Loyola, 2010.

Educação On-line. São Paulo: Loyola, 2. ed. 2006.

TORRES, T.; AMARAL, S. Aprendizagem colaborativa e Web 2.0: proposta de modelo de organização de conteúdos interativos. ETD - Educação Temática Digital, v. 12, n.esp., p. 49-72, mar. 2011. Dis- 
ponível em: http://www.fae.unicamp.br/revista/index.php/etd/article/view/2281. Acesso em: 27 abr. 2011.

Submetido para avaliação em 02 de janeiro de 2012.

Aprovado para publicação em 17 de outubro de 2013.

Nasson Paulo Sales Neves: Mestrando em Educação Brasileira pela Universidade Federal de Alagoas - Centro de Educação - Maceió-AL - Brasil.

E-mail: nassonpaulo@gmail.com 